\title{
Precis of Suffering and Virtue
}

\author{
Michael Brady ${ }^{1}$
}

Accepted: 14 September 2021 / Published online: 12 October 2021

(c) The Author(s) 2021

The book emerged from two projects at Glasgow where I was co-investigator with my colleague David Bain, and postdoc and now colleague Jennifer Corns. These were projects on the nature of pain (2012-13), and the value of suffering (2013-16). I would like to record my thanks to the John Templeton Foundation for their generous funding of these projects.

I was (and am) interested in philosophy of emotion, and in particular in gaining some understanding of issues that strike me as fascinating, issues that everyone understands, and yet have received relatively little philosophical attention. My 2013 book Emotional Insight was an investigation into the common-sense but relatively neglected idea that emotions have epistemic importance and value; in particular, they can tell us important things about the evaluative world. Suffering \& Virtue, and the project from which it emerged, had a similar tenor. I was interested in the question why we suffer. On the one hand, this represents a question about the causes of our negative affective states, and in this sense it is somewhat easy to answer. The more interesting question is of course the philosophical one: why do we suffer, in the sense of why have creatures like us developed, or been created, to experience pain, misery, hunger, heartache, frustration, and all of the myriad forms that suffering can take? What is the point of suffering? What (if anything) is its value, what (if anything) does it do? This is clearly an important philosophical question, one which concerns a central feature of human existence, but one which hadn't received much in the way of philosophical attention - although it has been the focus of a great deal of theological discussion and writings. So it is a question that was ripe for the asking, and the book is an attempt at presenting my answer.

Of course, it is important for books on such a broad topic as this to have a central organizing theme, and so my focus was, in the main, to account for the role that suffering can have in a good life, contrary to the prevailing wisdom that suffering is (always or typically) detrimental to happiness and well-being. Moreover, I attempted to narrow things further by attempting to answer the question within a virtue-theoretical framework. This is because forms of suffering struck me as sometimes appropriate or fitting responses to disvalue, evil, misfortune, and there

Michael Brady

michael.brady@glasgow.ac.uk

1 University of Glasgow, Glasgow, UK 
is a tradition of viewing virtues in this way: as appropriate responses to universal human conditions.

A virtue-theoretical account promised, moreover, to accommodate the dimensions of value that suffering can have - intrinsic, instrumental; to line-up nicely with some historical and theological approaches; and to accommodate the value that suffering can have for individuals and for groups. Even with this narrowing of focus, however, the book's main claims are of necessity rather general, and I suspect in many cases somewhat too general. A close focus on important contextual factors and details with respect to how suffering can enable a person or group to cultivate and develop virtue is - I now realise, and in large part thanks to the splendid work of the participants in this symposium - lacking. More needed to be said, and of course needs to be said, to fill in the contours of the picture I have sketched here, and I'm very grateful to my commentators for suggesting some ways in which this can happen, and places in which the overall view is problematic because detail is lacking. But with that rather large caveat in place, I'm remain somewhat convinced by the overall picture sketched, and the central claims made.

Here, in brief, is an outline of the book. In the first part, I give an account of what suffering is. On my view, suffering is a negative affective experience, and one that we desire to cease. (In a slogan: suffering is unpleasantness that we mind.) I give reasons in favour of this desire view of suffering in the first chapter, and in the second provide a defence of a desire view of unpleasantness, in terms of sensations that we desire to cease. I know that my commentators have concerns about the main ideas and details in both chapters, and so I clearly need to do more here to convince them of these views - or at least, to try to address some of the puzzles that the view generates.

The following chapters turn away from the nature of suffering, and to an investigation into how we might understand suffering's value on virtue-theoretical lines. (I know that Christian Miller has some worries about how the first and second parts of the book are related to each other. These are worries that occupy me as well!) I propose that there are three elements of the virtue-theoretical approach to the value of suffering.

1. Forms of suffering can constitute virtuous motives, and dispositions to have these feelings are virtues of various systems. Suffering here plays the vital epistemic and motivational roles that are central to virtue: to notice what we need to notice, to be moved to act accordingly in its presence. Forms of suffering constitute virtuous motives (or are forms of faculty virtues) because they outperform feasible competitors for these epistemic and motivational tasks. (In making this case, I focus on feelings of pain and remorse as instances of suffering.)

2. Suffering is central to the cultivation and development of a range of personal virtues to do with strength of character, such as fortitude, perseverance, courage; and virtues to do with vulnerability, such as creativity, humility (chapter 4). Suffering is also central to the cultivation and development of moral behaviour, involving compassion and empathy, and wisdom (chapter 5). All of these are vital to living a good life. In chapter $5 \mathrm{I}$ also respond to the criticism that there is something 
morally dubious about putting a 'positive spin' on suffering, that it is a form of moral insensitivity to suffering, and might increase burdens on those who suffer. (This is what Barbara Ehrenreich calls the 'tyranny of positive thinking'.) I agree with Ehrenreich that certain forms of positivity about suffering can indeed be guilty as charged here, but I hope that my account thus far is not one of them.

3. Suffering can be a virtue of social groups and systems, and thus essential to the proper functioning of these. This is achieved, in the main, through suffering's communicative value. I make the case by looking at accounts of the value of suffering that we get from certain religious traditions (punishment for sin, loving discipline, test of faith), and consider similar secular accounts (required for legitimate judicial punishment, evidence of love, initiation). I argue that suffering can promote justice, strengthen loving relationships, and ensure trust and faith, all of which are necessary for the proper functioning of social groups

None of this suggests that all suffering is good; or that the extent and amount of suffering always has an upside; or that this is the best of all possible worlds when it comes to suffering. Much suffering has no intrinsic or instrumental value, and we should do what we can to alleviate it. The ongoing covid pandemic is a clear instance of this, as my commentators rightly point out. But I think that the following remains true: for creatures like us, the development of virtue, and hence the good life, will be impossible without suffering in some forms or others.

Open Access This article is licensed under a Creative Commons Attribution 4.0 International License, which permits use, sharing, adaptation, distribution and reproduction in any medium or format, as long as you give appropriate credit to the original author(s) and the source, provide a link to the Creative Commons licence, and indicate if changes were made. The images or other third party material in this article are included in the article's Creative Commons licence, unless indicated otherwise in a credit line to the material. If material is not included in the article's Creative Commons licence and your intended use is not permitted by statutory regulation or exceeds the permitted use, you will need to obtain permission directly from the copyright holder. To view a copy of this licence, visit http://creativecommons.org/licen ses/by/4.0/.

Publisher's Note Springer Nature remains neutral with regard to jurisdictional claims in published maps and institutional affiliations. 